\title{
PC-EL TYPE THIN FILM OPTOELECTRONIC MEMORY SYSTEM
}

\author{
Z. PORADA \\ Institute of Electrical Engineering and Electronics, Technical University, Warszawska 24, 31-155 \\ Kraków (Poland) \\ E. SCHABOWSKA-OSIOWSKA AND T. KENIG \\ Department of Physics and Electron Technology, Institute of Electronics, Academy of Mining and \\ Metallurgy, Al. Mickiewicza 30, 30-059 Kraków (Poland) \\ (Received March 31, 1991; in final form April 22, 1991)
}

\section{INTRODUCTION}

PC-EL type thin film systems with optical feedback are interesting because of their possible application in optoelectronic logical systems.

In the simplest version the PC-EL system was obtained by series connection of a photoconducting element (PC) with an electroluminescent cell (EL). Such a system was supplied with a sinusoidal voltage with fixed amplitude and frequency. The input signal was in the shape of rectangular light pulses illuminating the PC element, and the output signal-the luminance of the light emitted from the electroluminescent cell (EL). A part of the output signal was directed to the input, thus an optical feedback occurred in the system.

For sufficiently high values of feedback coefficient the investigated PC-EL system was of a bi-stable character ${ }^{1.2}$. Simple, two-element PC-EL systems with optical feedback can be utilized among others in optoelectronic memory elements.

A diagram of an optoelectronic memory system is presented in Fig. 1. When the photoconducting element $\mathrm{PC}_{1}$ is illuminated with a light pulse, the voltage drop on the element is low and almost all voltage $U$ is imposed to the electroluminescent cell $\mathrm{EL}_{1}$, causing its luminance. Due to the optical feedback the electroluminescent cell illuminates the $\mathrm{PC}_{1}$ element, i.e., the $\mathrm{PC}_{1}-\mathrm{EL}_{1}$ system is in the state "switched on". On the other hand, the $\mathrm{PC}_{2}-\mathrm{EL}_{2}$ system is "switched off" and doesn't emit a light signal as long as the $\mathrm{PC}_{2}$ element is not illuminated.

\section{THEORETICAL CONSIDERATIONS}

A mathematical model suitable for analysing the properties of a PC-EL memory system is proposed using the equivalent circuit shown in Fig. 2. 


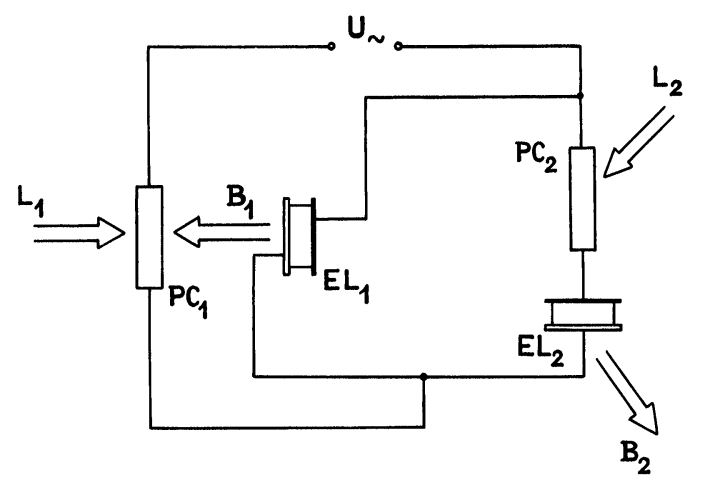

FIGURE 1 Diagram of an optoelectronic memory system

The admittance $\mathrm{Y}_{\mathrm{EL}}$ of electroluminescent cells $\mathrm{EL}_{1}$ and $\mathrm{EL}_{2}$ (assuming, that $\mathrm{Y}_{\mathrm{EL}}=\mathrm{Y}_{\mathrm{EL}_{1}}=\mathrm{Y}_{\mathrm{EL}_{2}}$ ) is described by the formula

$\mathrm{Y}_{\mathrm{EL}}=\mathrm{G}_{\mathrm{EL}}+\mathrm{j} 2 \pi \mathrm{fC} \mathrm{EL}_{\mathrm{E}}$

where $\mathrm{f}$ is the frequency of the alternating sinusoidal voltage supplying the PC-EL memory system, $\mathrm{G}_{\mathrm{EL}}$ is the leakage conductance of the electroluminescent cell and $\mathrm{C}_{\mathrm{EL}}$ is the capacitance of the cell.

The admittance $\mathrm{Y}_{\mathrm{PC}}$ of photoconductive elements $\mathrm{PC}_{1}$ and $\mathrm{PC}_{2}$ (assuming, that $\mathrm{Y}_{\mathrm{PC}}=\mathrm{Y}_{\mathrm{PC}_{1}}=\mathrm{Y}_{\mathrm{PC}_{2}}$ ) is given by the formula ${ }^{3}$

$\mathrm{Y}_{\mathrm{PC}}=\mathrm{G}_{0}+\frac{\mathrm{g}_{1} \mathrm{~L}_{\mathrm{TOT}}}{1+(2 \pi \mathrm{f} \tau)^{2}}+\mathrm{j} 2 \pi \mathrm{fC} \mathrm{CC}_{\mathrm{PC}}$

where $\mathrm{G}_{0}$ is the "dark" conductance of the photoconductive element, $\mathrm{g}_{1}$ and $\tau$ are parameters that are constant for a given photoconductive element, $\mathrm{C}_{\mathrm{PC}}$ is the ca-

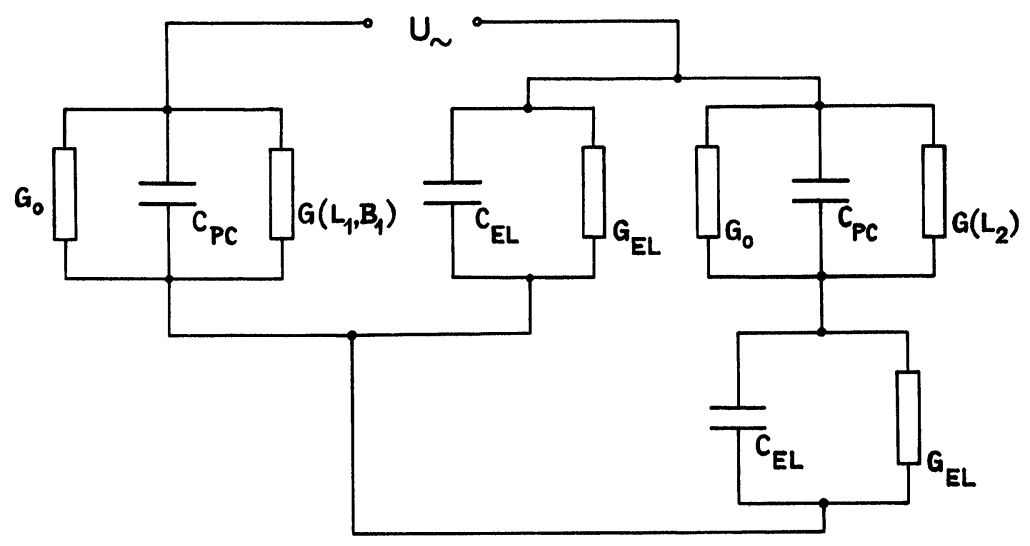

FIGURE 2 Equivalent circuit of a PC-EL system 
pacitance of the photoconductive element, and $\mathrm{L}_{\mathrm{TOT}}$ is the total illumination of the photoconductive element.

For a $\mathrm{PC}_{1}-\mathrm{EL}_{1}$ system with optical feedback

$\mathrm{L}_{\mathrm{TOT}}=\mathrm{L}_{1}+\beta \mathrm{B}_{1}$

where $L_{1}$ is the external illumination (input signal), $\beta$ is a constant determined by geometry and by the degree of spectral overlap of the electroluminescent cell $\left(\mathrm{EL}_{1}\right)$ and the photoconductive element $\left(\mathrm{PC}_{1}\right)$, and $\mathrm{B}_{1}$ is the luminance of the electroluminescent cell $\left(\mathrm{EL}_{1}\right)$.

For a $\mathrm{PC}_{2}-\mathrm{EL}_{2}$ system without optical feedback $\mathrm{L}_{\mathrm{TOT}}=\mathrm{L}_{2}$, where $\mathrm{L}_{2}$ is the external illumination (second input signal).

Alfrey and Taylor's formula ${ }^{4}$ was used to describe the luminances $\mathrm{B}_{1}$ and $\mathrm{B}_{2}$ :

$\mathrm{B}_{1}=\mathrm{B}_{0} \exp (-\gamma / \mathrm{f}) \exp \left\{-\mathrm{b} / \sqrt{\mathrm{U}_{\mathrm{EL}_{1}}}\right\}$

and

$\mathbf{B}_{2}=\mathbf{B}_{0} \exp (-\gamma / f) \exp \left\{-b / \sqrt{\mathrm{U}_{\mathrm{EL}_{2}}}\right\}$

where $\mathrm{B}_{0}, \gamma$ and $\mathrm{b}$ are constant parameters for given $\mathrm{EL}_{1}$ and $\mathrm{EL}_{2}$ electroluminescent cells,

$\mathrm{U}_{\mathrm{EL}_{1}}=\left|\frac{\mathrm{Y}_{\mathrm{PC}_{1}}}{\mathrm{Y}_{\mathrm{PC}_{1}}+\mathrm{Y}_{\mathrm{EL}_{1}}+\frac{\mathrm{Y}_{\mathrm{PC}_{2}} \mathrm{Y}_{\mathrm{EL}_{2}}}{\mathrm{Y}_{\mathrm{PC}_{2}}+\mathrm{Y}_{\mathrm{EL}_{2}}}}\right| \mathrm{U}_{0}$

and

$\mathrm{U}_{\mathrm{EL}_{2}}=\left|\frac{\mathrm{Y}_{\mathrm{PC}_{2}}}{\mathrm{Y}_{\mathrm{EL}_{2}}+\mathrm{Y}_{\mathrm{PC}_{2}}}\right| \mathrm{U}_{\mathrm{EL}_{1}}$

where $\mathrm{U}_{0}$ is the amplitude of the voltage supplying the memory system.

For real PC-EL systems as well as for the frequencies not higher than $5000 \mathrm{~Hz}$, three additional simplifying assumptions are usually fulfilled:

$$
\mathrm{C}_{\mathrm{PC}} \ll \mathrm{C}_{\mathrm{EL}},\left(\mathrm{C}_{\mathrm{EL}}=\mathrm{C}\right), 2 \pi \mathrm{fC}_{\mathrm{EL}} \gg \mathrm{G}_{0}, 2 \pi \mathrm{fC}_{\mathrm{EL}} \gg \mathrm{G}_{\mathrm{EL}} \text { and }(2 \pi \mathrm{f} \tau)^{2} \ll 1 \text {. }
$$

Then the dependence of the average value $B_{1}$ of the luminance on the external intensity $\mathrm{L}_{1}$ and $\mathrm{L}_{2}$ of illumination can be expressed as follows:

$$
B_{1}=B_{0} \exp (-\gamma / f) \exp \left\{-\frac{b}{\sqrt{U_{0}}}\left[x_{1}^{2}+\left(\frac{x_{2}}{G_{0}+g_{1}\left(L_{1}+\beta B_{1}\right)}\right)^{2}\right]^{1 / 4}\right\}
$$


and

$\mathrm{B}_{2}=\mathrm{B}_{0} \exp (-\gamma / f) \exp \left\{-\frac{\mathrm{b}}{\sqrt{\mathrm{U}_{0}}}\left[\mathrm{x}_{3}\left\{\mathrm{x}_{1}^{2}+\left(\frac{\mathrm{x}_{2}}{\mathrm{G}_{0}+\mathrm{g}_{1}\left(\mathrm{~L}_{1}+\beta \mathrm{B}_{1}\right)}\right)^{2}\right\}\right]^{1 / 4}\right\}$

where

$\mathrm{x}_{1}=1+\frac{(2 \pi \mathrm{fC})^{2}}{\left[\mathrm{G}_{0}+\mathrm{g}_{1}\left(\mathrm{~L}_{1}+\beta \mathrm{B}_{1}\right)\right]^{2}+(2 \pi \mathrm{fC})^{2}}$

$x_{2}=2 \pi f C+\frac{2 \pi f C\left(G_{0}+g_{1} L_{2}\right)^{2}}{\left(G_{0}+g_{1} L_{2}\right)^{2}+(2 \pi f C)^{2}}$,

and

$x_{3}=\frac{\left(G_{0}+g_{1} L_{2}\right)^{2}}{\left(G_{0}+g_{1} L_{2}\right)^{2}+(2 \pi f C)^{2}}$.

\section{EXPERIMENTAL DETAILS AND RESULTS}

A thin film PC-EL optoelectronic memory element was made by vacuum evaporating photoconductive and electroluminescent layers. The photoconductive element (Fig. 3) was prepared as a sandwich-type system on a Corning 7059 glass substrate.

The first layer was a transparent electrode of tin-doped $\operatorname{In}_{2} \mathrm{O}_{3}$, obtained by the reactive cathode sputtering of $90 \% \mathrm{In}-10 \% \mathrm{Sn}$ alloy. The second layer was a

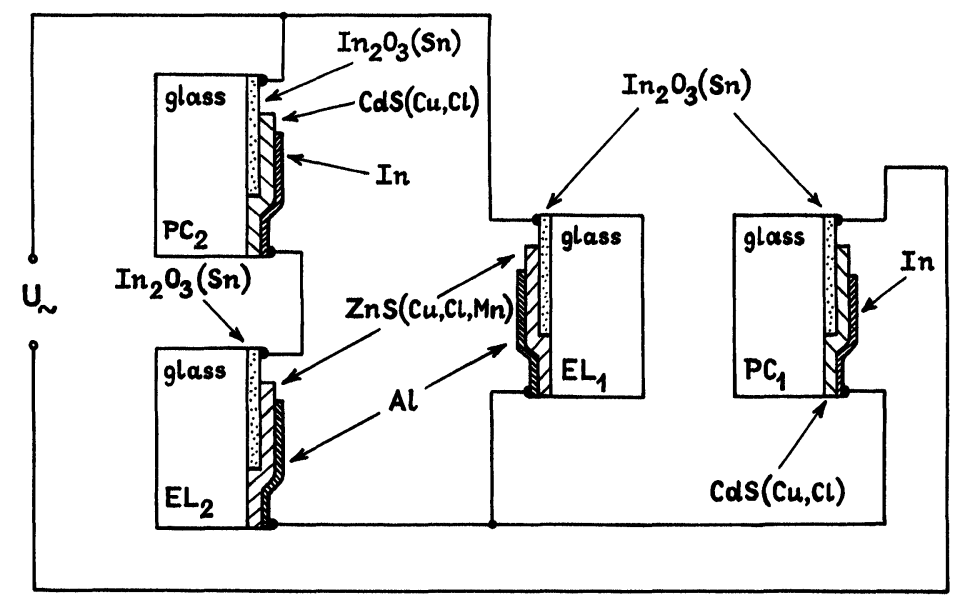

FIGURE 3 Arrangement of the thin film PC-EL systems of an optoelectronic memory element 
photoconductive CdS film ${ }^{5}$ doped with copper and chlorine and evaporated under vacuum at a pressure of $6.7 \times 10^{-3} \mathrm{~Pa}$.

The electroluminescent cell (Fig. 3), was a thin film capacitor with an average thickness of $0.85 \mu \mathrm{m}$ produced by the vacuum evaporation of copper-, chlorineand manganese-doped $\mathrm{ZnS}^{6}$. The lower transparent conducting electrode was tindoped $\operatorname{In}_{2} \mathrm{O}_{3}$ on a glass substrate, while the upper electrode was a vacuum-evaporated thin aluminium film.

The experimental values of the parameters of the photoconductive element and electroluminescent cell were found to be as follows:

$\begin{array}{ll}\mathrm{G}_{0} & 8 \times 10^{-9} \Omega^{-1} \\ \mathrm{~g}_{1} & 2.38 \times 10^{-7} 1 \mathrm{x}^{-1} \Omega^{-1} \\ \tau & 3.1 \times 10^{-5} \mathrm{~s} \\ \mathrm{C}_{\mathrm{PC}} & 6.5 \times 10^{-11} \mathrm{~F} \\ \mathrm{~b} & 16.09 \mathrm{~V}^{1 / 2} \\ \gamma & 951 \mathrm{~s}^{-1} \\ \mathrm{~B}_{0} & 104{\mathrm{~cd} . \mathrm{m}^{-2}} \\ \mathrm{C}_{\mathrm{EL}} & 2.8 \times 10^{-9} \mathrm{~F} \\ \mathrm{G}_{\mathrm{EL}} & 7.4 \times 10^{-8} \Omega^{-1}\end{array}$

and

$\beta \quad 0.781 \mathrm{x} \cdot \mathrm{m}^{2} \mathrm{~cd}^{-1}$.

Figure 4 shows the spectral distribution of the electroluminescence for the $\mathrm{ZnS}(\mathrm{Cu}, \mathrm{Cl}, \mathrm{Mn})$ layer and the spectral response of the $\mathrm{CdS}(\mathrm{Cu}, \mathrm{Cl})$ photoconductive layer.

The theoretical analysis shows that a $\mathrm{PC}_{1}-\mathrm{EL}_{1}$ system with optical feedback may be a bi-stable system on the condition that the feedback coefficient $\beta$ will have a value higher than $\beta_{\mathrm{LIM}}{ }^{7}$.

Results from previous investigations ${ }^{2,7}$ show that the limiting value $\beta_{\text {LIM }}$ depends on the frequency of voltage supplying the $\mathrm{PC}_{1}-\mathrm{EL}_{1}$ system (Fig. 5).

If a $\mathrm{PC}_{1}$ element will be illuminated with an input signal $\mathrm{L}_{1}$, then at the output of the bi-stable $\mathrm{PC}_{1}-\mathrm{EL}_{1}$ system a signal $\mathrm{B}_{1}$ will appear in the shape of the light emitted from the electroluminescent cell $\mathrm{EL}_{1}$, which additionally will illuminate the $\mathrm{PC}_{1}$ element. When the output signal $\mathrm{B}_{1}$ will not fall to zero, in spite of switching off the input signal $\mathrm{L}_{1}$, then the $\mathrm{PC}_{1}-\mathrm{EL}_{1}$ system will be in the state "switched on", that is to say it will have a memory it was previously illuminated with the input signal $\mathrm{L}_{1}$.

In Fig. 6 the dependence of the output signal $B_{1}$ on the frequency of voltage supplying the $\mathrm{PC}_{1}-\mathrm{EL}_{1}$ system for various amplitudes of this voltage is presented 


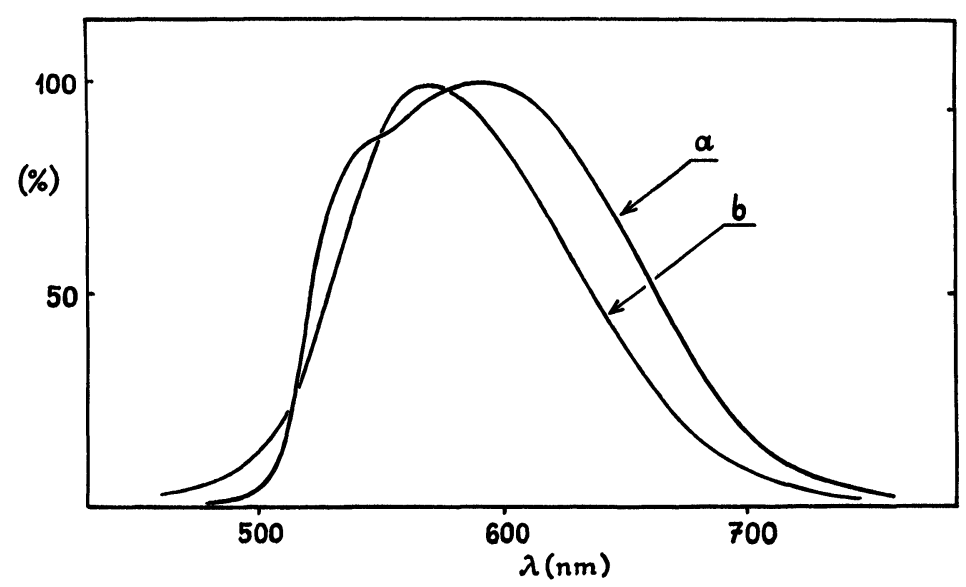

FIGURE 4 Spectral distribution I [\%] vs. $\lambda[\mathrm{nm}]$ of the sensitivity of the $\mathrm{CdS}(\mathrm{Cu}, \mathrm{Cl})$ photoconductive layer (curve a) and of the electroluminescence of the $\mathrm{ZnS}(\mathrm{Cu}, \mathrm{Cl}, \mathrm{Mn}$ ) layer (curve b)

for a system being in the state of "switched on" (i.e. for $\mathrm{L}_{1}=0$ ). The dependence of the output signal $B_{1}$ on the input signal $L_{1}$ for the bi-stable $P_{1}-E_{1}$ system is presented in Fig. 7.

This characteristic shows a good agreement with the theoretical curve represented by the equation (8) for $\mathrm{L}_{2}=0$.

Assuming the $\mathrm{PC}_{1}-\mathrm{EL}_{1}$ system to be in the state "switched on", the application of the second input signal $\mathrm{L}_{2}$, illuminating the $\mathrm{PC}_{2}$ element, will cause the appearance of the output signal $\mathrm{B}_{2}$ in the form of a light emitted from the electroluminescent cell $\mathrm{EL}_{2}$. As the $\mathrm{PC}_{2}-\mathrm{EL}_{2}$ system is one without optical feedback, the

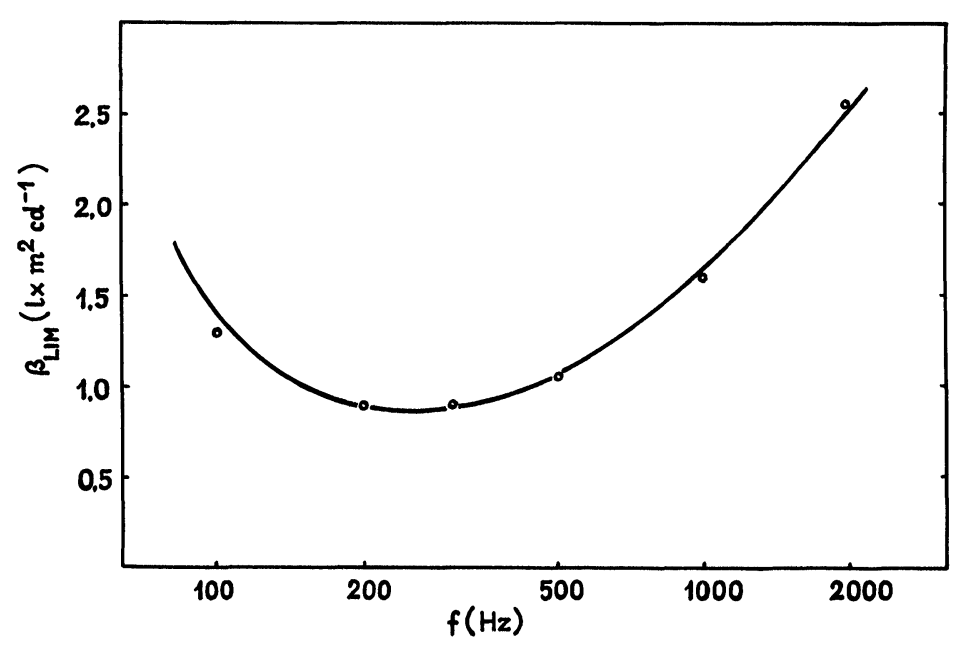

FIGURE 5 Dependence of the coefficient $\beta_{\text {LIM }}$ on the frequency 


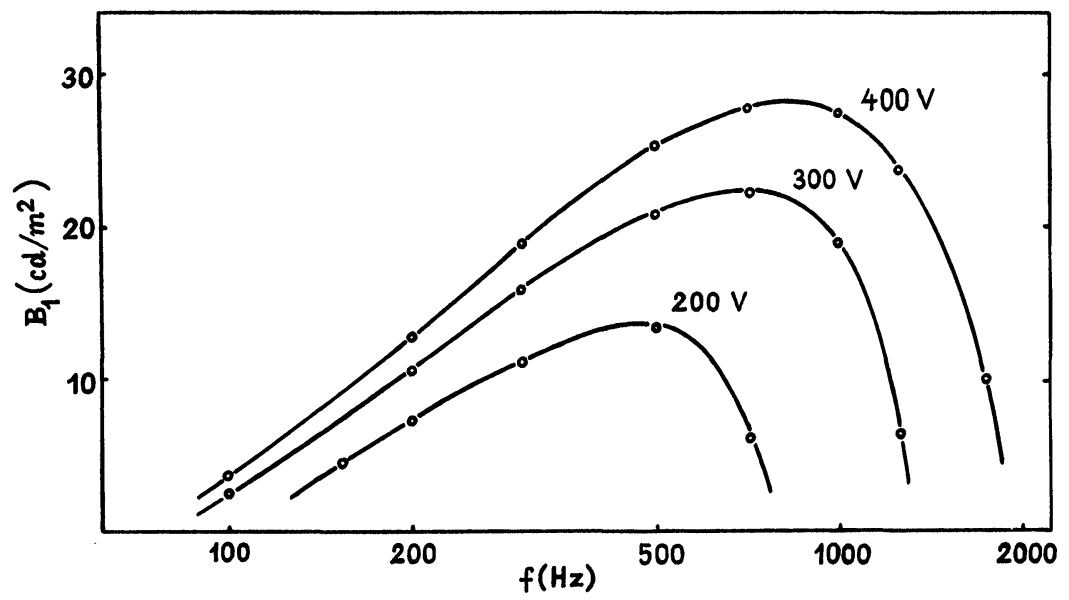

FIGURE 6 Dependence of the output signal $B_{1}$ on the frequency of voltage supplying the $P C_{1}-E L_{1}$ system for various amplitudes of this voltage

breaking off of the input signal $\mathrm{L}_{2}$ will result every time in the decay of the output signal $\mathrm{B}_{2}$ to a value not far from zero.

According to equation (8), for the $\mathrm{PC}_{1}-\mathrm{EL}_{1}$ system $\left(\mathrm{L}_{1}=0, \mathrm{~B}_{1}>0\right)$ the output signal $B_{2}$ depends on the value of the input signal $L_{2}$, the amplitude of the voltage supplying the system, and its frequency.

In Fig. 8 the dependence of the output signal $\mathrm{B}_{2}$ on the input signal $\mathrm{L}_{2}$ for various values of amplitude of supplying voltage and fixed value of frequency ( $f=300$ $\mathrm{Hz}$ ) is presented.

The dependence of the output signal $\mathrm{B}_{2}$ on the frequency for a fixed value of amplitude of supplying voltage as well as for several values of input signal $\mathrm{L}_{2}$, is shown in Fig. 9.

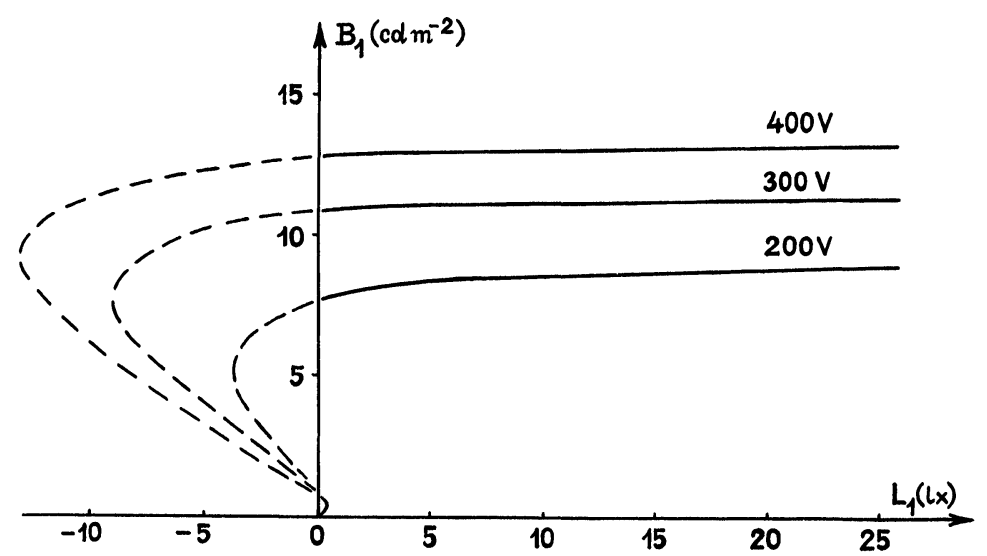

FIGURE 7 Dependence of the output signal $B_{1}$ on the input signal $L_{1}$ for the bi-stable $P C_{1}-E L_{1}$ system 


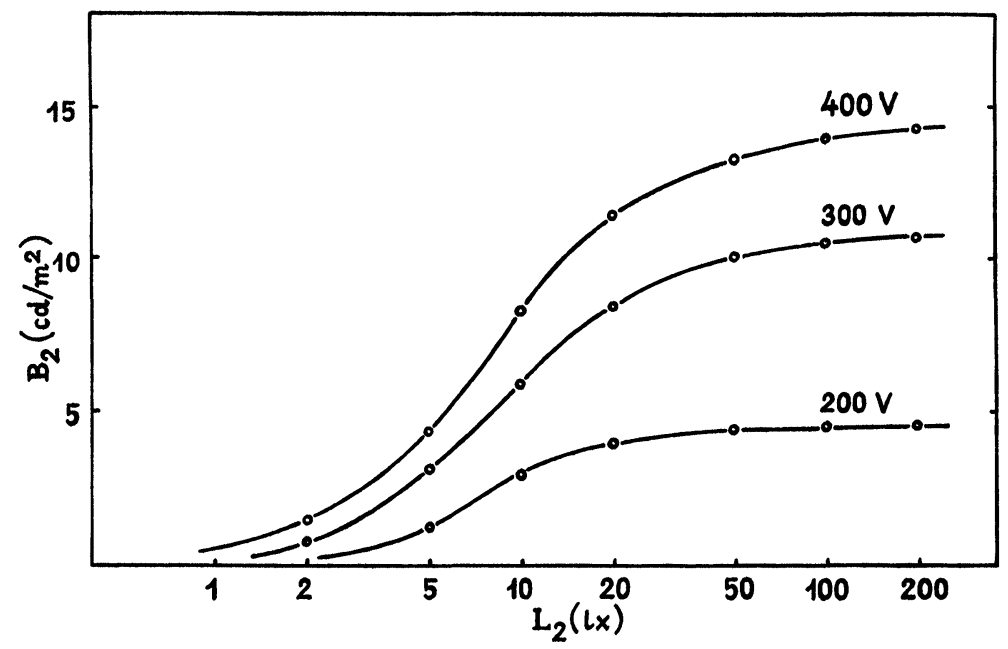

FIGURE 8 Dependence of the output signal $B_{2}$ on the input signal $L_{2}$ for various values of amplitude of supplying voltage at fixed value of frequency $(f=300 \mathrm{~Hz})$

In an optoelectronic memory system of PC-EL type switching on of an input signal $L_{2}$ influences not only the value of the output signal $B_{2}$, but also the value of signal $\mathrm{B}_{1}$ (equation 8 ).

In Fig. 10 the dependence of signal $B_{1}$ on the input signal $L_{2}$ for various values of amplitude of supplying voltage and its fixed frequency, and in Fig. 11 the dependence $B_{1}$ on $L_{2}$ for various frequencies and fixed value of voltage amplitude are presented.

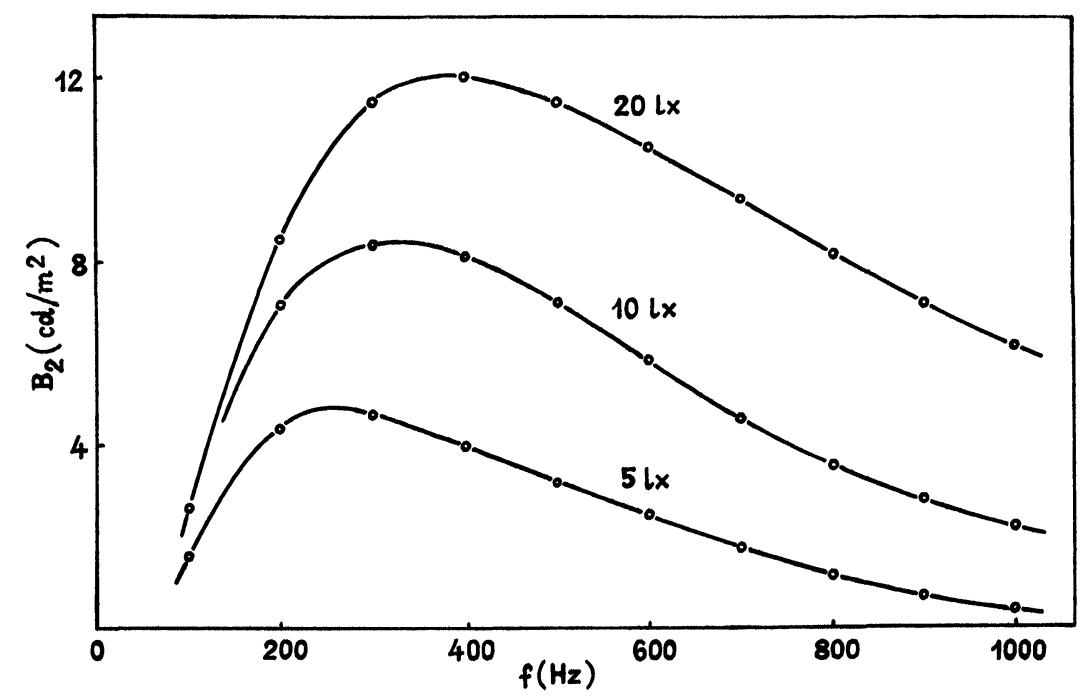

FIGURE 9 Dependence of the output signal $\mathrm{B}_{2}$ on the frequency at fixed value of amplitude of supplying voltage $\left(\mathrm{U}_{0}=400 \mathrm{~V}\right)$ for several values of the input signal $L_{2}$ (the $P C_{1}-E L_{1}$ system is in the state "switched on") 


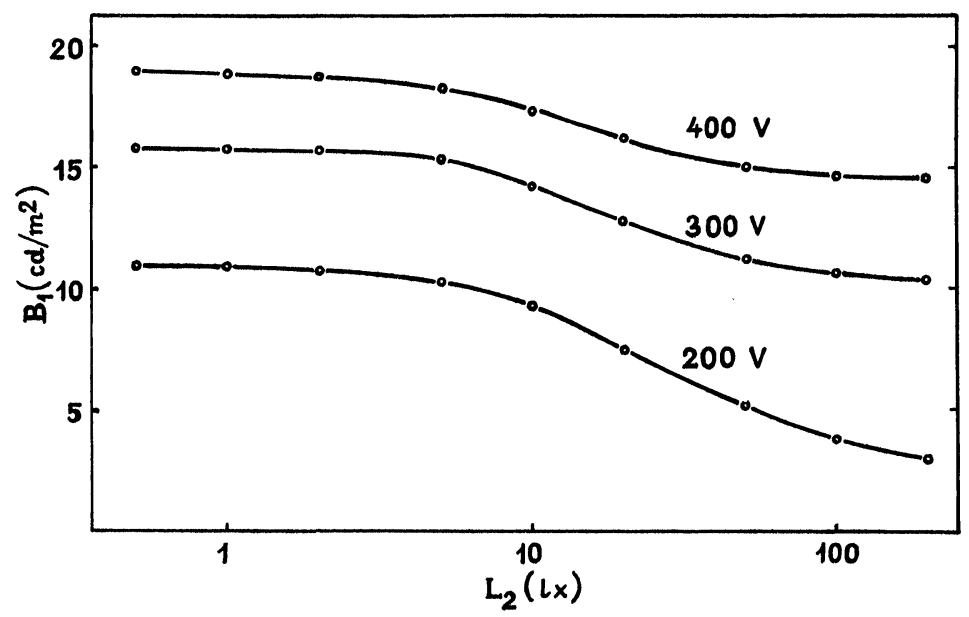

FIGURE 10 Dependence of the signal $B_{1}$ on the input signal $L_{2}$ for various values of amplitude of supplying voltage at its fixed frequency $(\mathrm{f}=300 \mathrm{~Hz})$

\section{CONCLUSIONS}

Results of experimental investigations, as well as from the analysis of proposed theoretical model, indicate that the thin film PC-EL type system presented in this work can act as an optoelectronic memory element under following conditions: -the $\mathrm{PC}_{1}-\mathrm{EL}_{1}$ system should have an optical feedback with feedback coefficient allowing to transpose it in "switched on" state,

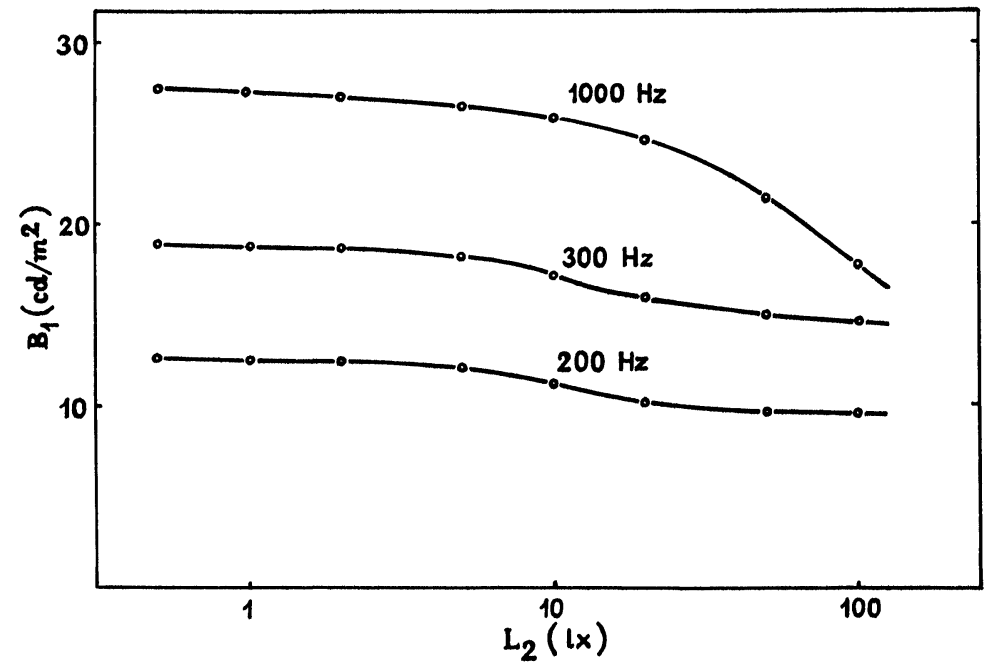

FIGURE 11 Dependence of the signal $B_{1}$ on the input signal $L_{2}$ for various frequencies at fixed value of voltage amplitude $\left(\mathrm{U}_{0}=400 \mathrm{~V}\right)$ 
- the $\mathrm{PC}_{2}-\mathrm{EL}_{2}$ system should be a system without feedback. In an optoelectronic memory element the $\mathrm{PC}_{1}-\mathrm{EL}_{1}$ system being in the "switched on" state can be switched off only by cutting off the voltage supplying this element.

The magnitude of input signal $\mathrm{L}_{1}$ should be high enough to transpose the $\mathrm{PC}_{1}$ $\mathrm{EL}_{1}$ system in the "switched on" state. For investigated system this state was being obtained at $\mathrm{L}_{1}$ signal value as low as of the order of several luxes.

Considering the required value of output signal $\mathrm{B}_{2}$ of the order of several $\mathrm{cd} /$ $\mathrm{m}^{2}$, the second input signal $\mathrm{L}_{2}$ should have a value in the range of 10 to $20 \mathrm{~lx}$, whereas the frequency of the supplying voltage should be about $300 \mathrm{~Hz}$ and its amplitude not lower than $400 \mathrm{~V}$.

\section{REFERENCES}

1. Z. Porada and E. Schabowska-Osiowska, Thin Solid Films, 164, 411 (1988).

2. Z. Porada and E. Schabowska-Osiowska, Active and Passive Elec. Comp. 13, 151 (1988).

3. Z. Porada and E. Schabowska, Thin Solid Films, 65, 137 (1980).

4. G.F. Alfrey and J.B. Taylor, Br. J. Appl. Phys., 4, 44S (1955).

5. Z. Porada and E. Schabowska, Thin Solids Films, 66, L55 (1980).

6. Z. Porada and E. Schabowska, J. Lumin., 21, 129 (1980).

7. Z. Porada, Thin Solid Films, 109, 213 (1983). 

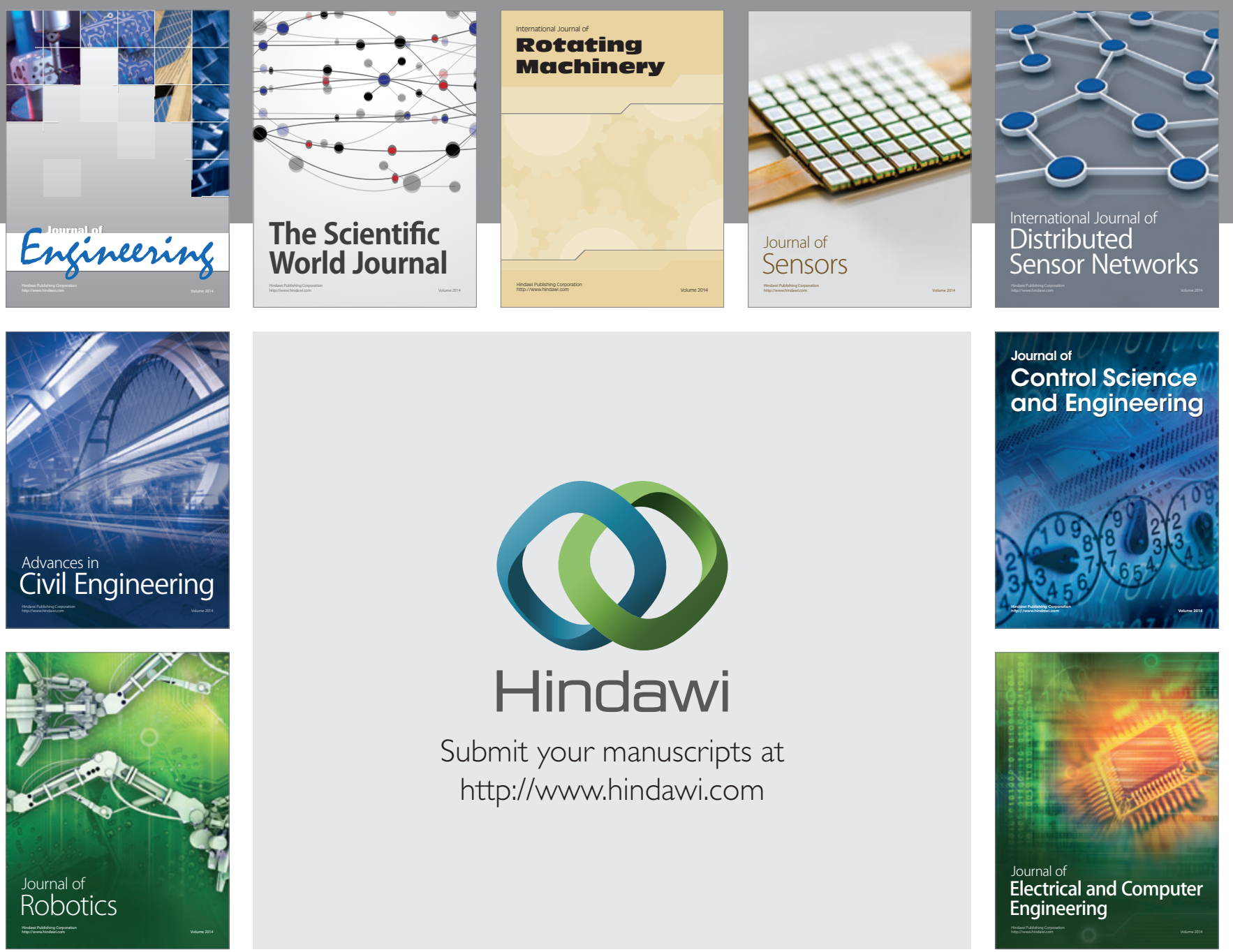

Submit your manuscripts at

http://www.hindawi.com
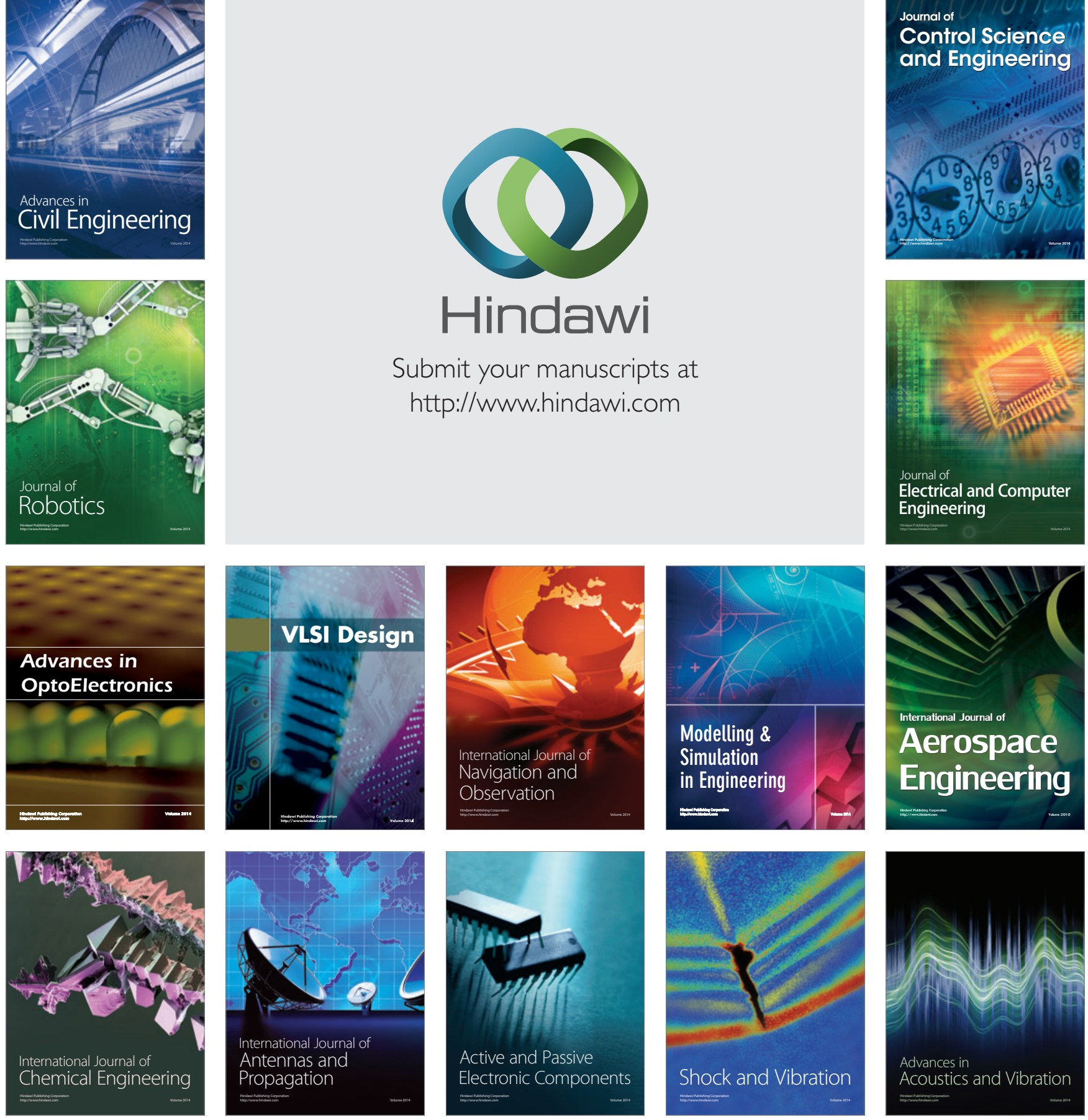